\title{
Pakistan human resources for health assessment, 2009
}

A. Hafeez, ${ }^{1}$ Z. Khan, ${ }^{2}$ K.M. Bile, ${ }^{2}$ R. Jooma ${ }^{3}$ and M. Sheikh ${ }^{4}$

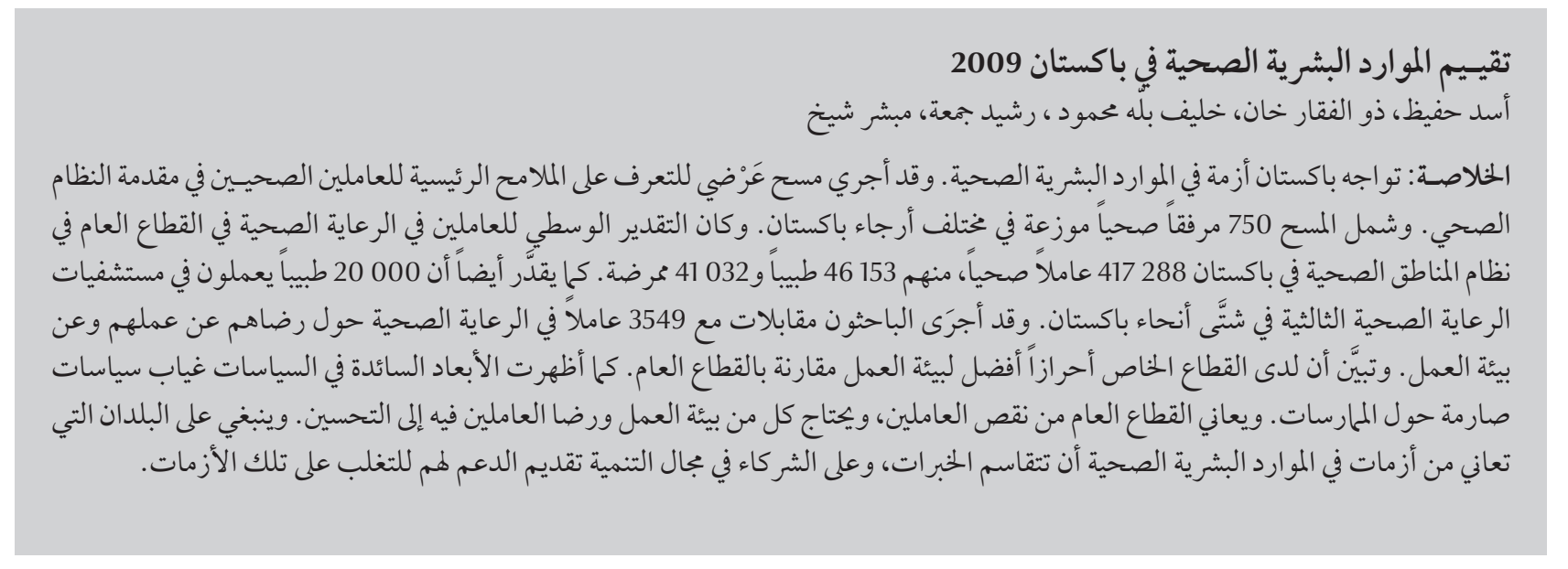

ABSTRACT Pakistan faces a human resources for health ( $\mathrm{HRH}$ ) crisis. A cross-sectional survey was conducted to overview frontline health workers. A total of 750 health facilities were surveyed across Pakistan. The median estimate of public sector health care workers in the district health system in Pakistan is 417 288, including 46153 doctors and 41032 nurses. Another estimated 20000 doctors work in public sector tertiary care hospitals across the country. A total of 3549 health care workers were interviewed regarding job satisfaction and work environment. The private sector had better work environment scores compared with the public sector. Policy dimensions showed an absence of robust policies in practice. The public sector is inadequately staffed and job satisfaction and work environment need improvement. HRH crisis countries should share experiences, and developmental partners should support them in overcoming the HRH crisis.

\section{Évaluation des ressources humaines pour la santé au Pakistan en 2009}

RÉSUMÉ Le Pakistan est confronté à une crise des ressources humaines pour la santé. Une étude transversale a été réalisée sur les agents de santé en première ligne dans 750 établissements de soins pakistanais au total. Le système de santé de district pakistanais compte environ 417288 agents de santé dans le secteur public, dont 46153 médecins et 41032 infirmières, Selon une estimation, 20000 médecins travaillent dans les hôpitaux de soins tertiaires du secteur public dans tout le pays. Au total, 3549 agents de soins de santé ont été interrogés sur leur satisfaction et leur environnement professionnels. Le secteur privé a obtenu de meilleurs résultats que le secteur public en termes d'environnement de travail. Sur le plan politique, il a été démontré qu'aucune stratégie solide n'était mise en pratique. Le secteur public manque de personnel, et l'environnement de travail et la satisfaction des employés ont besoin d'être améliorés. Les pays affrontant une crise des ressources humaines pour la santé devraient partager leurs expériences. En outre, il serait souhaitable que des partenaires du développement les soutiennent afin de surmonter cette crise. 


\section{Introduction}

The World Health Organization (WHO) has defined the health workforce as "all people primarily engaged in actions with the primary intent of enhancing health". This definition is consistent with the WHO definition of health systems as comprising all activities with the primary goal of improving health. The health workforce is one of the most important pillars of the health system. Adequate numbers and quality of health workers have been positively associated with successful implementation of health interventions, including immunization coverage, outreach of primary care, and infant, child and maternal survival. [1].

Pakistan needs to gauge strategically the challenges to its health system, keeping in view:

- demographic trends, such as the increase in population to around 295 million by 2030 at the current population growth rate of $1.8 \%$ [2];

- the increase in life expectancy, rapid urbanization and epidemiological transition;

- the increased burden of chronic diseases such as cardiovascular diseases and cancers;

- trauma due to accidents, particularly among poor, disadvantaged and high-risk groups in the community [3].

- The health workforce should not only be depicted in terms of numbers of doctors, nurses and dentists, etc. expressed per 1000 population, it should also give due consideration to expected epidemiological transition, equitable distribution, new cadres, proper skill mix and types and nature of services to be delivered, as well as their demographic distribution. It is clear that, without prompt action, the human resources for health (HRH) crisis will worsen and health systems will be weakened even further [4].
Pakistan has been categorized as one of 57 countries that are facing an $\mathrm{HRH}$ crisis, below the threshold level defined by WHO to deliver the essential health interventions required to reach Millennium Development Goals (MDGs) by 2015 [5].

Health workforce strategy is usually low on a country's agenda, despite the understanding that scaling-up health interventions to reach MDGs is not possible without a minimum level of health workforce. National health workforce strategies require reliable and timely information, rational system analysis and a firm knowledge base. However, data analysis, research on HRH and technical expertise are still underdeveloped in many countries, in part due to low investment in HRH [6].

Pakistan's new draft National health policy 2009 mandated the development of strategies in various key areas, including HRH [7]. To develop evidencebased policy and a strategic framework, data on HRH are desperately required. Therefore, a countrywide HRH assessment was undertaken. The objectives of this study were to collect data on the numbers and distribution of the health workforce, to gather information about HRH management and policy, to collect data on job satisfaction among the health workforce, and to gather information on the HRH work environment.

\section{Methods}

A cross-sectional survey was carried out throughout Pakistan over a period of 4 months (September-December 2009). The total sample size was 750 health facilities, with equal numbers from the public and private sectors. In order to obtain a representative sample, four districts from each province were selected at random. Since the sampling frame for the public sector facilities in each district was known, a random sample of 22 facilities in the public sector was chosen from each study district.
Private sector facilities were classified as hospitals (having an indoor facility) and clinics (with only outpatient consultation) and a similar number was chosen from each district. An estimate of the total number of postgraduate trainee doctors, faculty members of medical schools and medical officers of tertiary care hospitals in the public sector was also obtained from the largest postgraduate training body in the country, the College of Physicians and Surgeons Pakistan, Karachi, the Pakistan Medical and Dental Council and major tertiary hospitals, respectively.

The tools for data collection were adopted and customized from available questionnaires obtained during a literature search. Four types of tools were used: a data collection form for numbers and distribution, and questionnaires for HRH management policies, work environment and job satisfaction. Pilot testing and validity checks were carried out for all tools before the survey and appropriate changes made based on feedback. The survey teams were trained on use of the tools in three stages. The first stage was a master training workshop in Islamabad, followed by provincial workshops to train district field surveyors. Supervisors were also given supervision training.

Data were collected from federal and provincial health ministries, vertical programmes and executive district officer health offices on numbers and distribution of health workers, job satisfaction and work environment. However, questionnaires on HRH policy were only administered in federal/provincial ministries and large private hospitals in provincial capitals. In each category, $10 \%$ of the health workforce in every sampled health facility (not exceeding a total of six in each category) were administered the job satisfaction and work environment questionnaires.

Each health worker included in the survey was asked 32 questions on job satisfaction and 34 questions on work environment. Their response to 
each question was scored as follows: 1 = agree; $2=$ somewhat agree; $3=$ neutral; $4=$ somewhat disagree; and $5=$ disagree. A lower score was therefore associated with agreement and higher scores with increasing levels of disagreement. Individual questions were grouped by aspect covered into several composite indices and the means of the responses for these composite indices were reported. Each question carried equal weight.

The HRH policy questionnaire was used for interviewing senior managers from the public and private health sectors, at federal and provincial levels. In the public sector, in each province a senior manager from the offices of the Director General Health was interviewed. In the private sector, a senior manager from a private hospital was interviewed in each province. Interviews focused on the stages of the $\mathrm{HRH}$ management policy/plan and its implementation across various aspects of HRH management. The five main areas of the questionnaire were: HRH management capacity; HRH data; personnel policy and practice; performance management; and training. On each of 24 components within these five areas, respondents were asked to rate the stage their organization had achieved, and to indicate the level of policy development, from "no policy developed" to "more than five years of experience" in the particular policy area related to the component. Within each area, all the specific components for making a judgement for the organization were analysed.

Comprehensive data quality checks were performed during data collection and data entry. To reduce the number of non-respondents at the point of data collection and other reporting errors, the following steps were adopted:

- introductory letters were sent to all concerned prior to initiation of field activity;

- an ID card was assigned to each field surveyor;
- interviewing techniques were part of surveyor training at the province level;

- verbal consent was obtained from respondents;

- connection between the district and provincial focal person was established in order to address discrepancies that may have arisen during the survey;

- detailed microplans indicating the number and location of health care facilities to be visited on a daily basis were provided to enumerators;

- full details of the enumerator, including contact details, were provided to facilities and provincial data coordinators.

\section{Survey monitoring}

A "central monitoring cell" was established in the federal Ministry of Health to oversee the process of data collection, supervise the provincial focal persons/survey coordinators and monitor the survey enumerators to resolve any issues at the grass-root level. Data collection was monitored on a daily basis to assess the progress and implementation of the survey plan. The data entry team supervisors were instructed to communicate with the survey enumerators at 12:00 and at 16:00 daily, collect any faulty questionnaires and report to the survey coordinators twice a day to resolve any issues and correct discrepancies. In addition, the flagged faulty questionnaires were sent back to be refilled by the survey enumerators. Data entry was successfully completed in the first week of December 2009.

\section{Data analysis}

Data were cleaned and validated in Islamabad, before being transferred to an analysis team in Bethesda, Maryland, United States of America. Data were originally entered into SPSS software (SPSS Inc.) and converted to the Stata version 9 format (StataCorp) for analysis. Further analysis and charting was also carried out using Microsoft Excel' (Microsoft Corp.).

In view of the data quality issues in the public sector records that were experienced during this assessment, an extrapolation analysis was also conducted for various cadres; for example, to calculate the total number of doctors for any province, the average of sampled facilities was obtained by dividing the number of doctors in the sampled facilities by the number of facilities surveyed. This sample average was then multiplied by the total number of respective facilities in the province or region to obtain the total estimated number of doctors. This methodology was also helpful in obtaining national consolidated figures for unsampled regions.

\section{Results}

Results are given in two sections: the first deals with the numbers and distribution of health workers in the public sector and HRH policy analysis; the second describes the findings about job satisfaction and work environment in both the public and private sectors.

\section{Numbers and distribution of health workers in the public sector and HRH policies}

Table 1 shows the types of 349 district health facilities in the public sector from which data on numbers and distribution were collected. Data for these 349 facilities were also collected from the office of the executive district officer (health) for cross-checking, giving two data points for most facilities. In addition, consolidated data on health workers were collected from the federally funded programmes, which have district-level implementation. There were a large number of basic health units in the sample. The oversampling of basic health units is rationalized, as this is the most numerous type of public health facility in Pakistan. 


\begin{tabular}{|c|c|c|c|c|c|c|c|}
\hline Province & DHQs & THQs & RHCs & BHUs & Dispensaries & МСHC & Total \\
\hline Balochistan & 3 & 2 & 10 & 59 & 13 & 5 & 92 \\
\hline Khyber Pakhtunkhwa & 4 & 3 & 6 & 61 & 4 & 5 & 83 \\
\hline Punjab & 4 & 4 & 8 & 62 & 4 & 4 & 86 \\
\hline Sindh & 4 & 4 & 8 & 44 & 24 & 4 & 88 \\
\hline Total & 15 & 13 & 32 & 226 & 45 & 18 & 349 \\
\hline
\end{tabular}

$D H Q s=$ district headquarters; $T H Q s=$ tehsil headquarters; $R H C S=$ rural health centres; $B H U s=$ basic health units; $M C H C=$ mother and child health centres.

Table 2 presents the median estimates of total HRH in the public sector by provinces and administrative areas of Pakistan. These estimates are based on district-level facility averages for health workers. These do not include tertiary hospitals, planning, supervisory, training and budgetary staff in federal, provincial and district health offices. From the total front-line public sector health workers, doctors and nurses are separated for further analysis, to illustrate the median estimate of doctors and nurses in the district health system in Pakistan in the public sector. Sindh province has the maximum number of doctors in the public sector, whereas Punjab has the maximum number of nurses, including midwives and lady health visitors, in the public sector.

In a separate exercise, data collected from the College of Physicians and Surgeons Pakistan, the Pakistan Medical and Dental Council and from major tertiary care hospitals revealed an estimate of 20000 doctors working as postgraduate trainees, faculty members and medical officers in public sector facilities. About $50 \%$ of these are located in Punjab, 30\% in Sindh and the remainder in the other two provinces.

In the absence of other measures of the adequacy of front-line health workers, the population ratio is a proxy indicator for adequacy. Table 3 depicts district-level doctor:population and nurse:population ratios.

Other estimates indicate that there are 2.1 managers and administrative staff for every 100 health workers of all other cadres. The five-year total of attrition due to resignations, long-leaves, retirement and deaths does not exceed $4 \%$ of the annual stock (using median stock for 2009 as a baseline) in most provinces for all the cadres.

The responses from our sample of interviewees in HRH management

$\begin{aligned} & \text { Table 2 Estimated median numbers of total health workers, doctors and nurses } \\
& \text { working in the district health system in the public sector in }\end{aligned}$
\begin{tabular}{lrrr}
\hline Province/area & Total health care workers & Doctors $^{\mathbf{a}}$ & Nurses $^{\mathbf{b}}$ \\
\hline Balochistan & 14538 & 1409 & 1892 \\
Khyber Pakhtunkhwa & 55646 & 7518 & 8783 \\
Punjab & 91696 & 12601 & 17773 \\
Sindh & 95263 & 20639 & 8169 \\
Islamabad Capital Territory & 1712 & 287 & 318 \\
Azad Jammu and Kashmir & 12931 & 987 & 1246 \\
Northern areas & 7267 & 741 & 1021 \\
Total for Pakistan & 417288 & 46153 & 41032 \\
\hline
\end{tabular}

${ }^{a}$ Doctors include general practitioners and specialists.

${ }^{b}$ Nurses include midwives and lady health visitors.

'This is not the sum of the individual medians and also includes federal vertical programmes (100 000 lady health workers).

positions indicate that provinces are at different levels of achievement in developing HRH management capacity and systems; this achievement varies from no policy experience to extensive experience of more than five years. The private facility managers interviewed also had varying levels of achievement. The private hospital managers interviewed in Sindh reported the strongest achievement with recent policy implementation experience. Similarly, private hospital managers from Punjab also reported strong achievement on some components, e.g. establishing an Oraclebased hospital information system for employee data.

\section{Job satisfaction and work environment}

Regarding job satisfaction and work environment, 3549 health care workers across public and private health facilities in Pakistan were interviewed, about $40 \%$ from the private sector and the remainder from the public sector. The urban:rural distribution was 48\%:52\%.

Table 4 compares the results on job satisfaction and work environment indices for the public:private sectors and urban:rural distribution. The general direction of the public sector scores is towards neutrality, with health workers neither agreeing nor disagreeing with the questions related to positive aspects of job satisfaction. Across the entire sample (public and private), comparisons for age, gender, location (urban/rural), provinces, basic pay scale (BPS) cadres for federal and provincial health workers, job type (regular/contractual) and years of service only show subtle differences in job satisfaction levels.

Work environment comparisons were also carried out across age, gender, location (urban/rural), BPS cadres for federal and provincial health workers, job type (regular/contractual) and years of service. No significant 


\begin{tabular}{lcccccc}
\hline $\begin{array}{l}\text { Table } 3 \text { Estimated district level public sector doctors and nurses per } 1000 \text { of } \\
\text { population in } 2009\end{array}$ & Min. & Median & Max. & Min. & Median & Max. \\
\hline Province/Area & 0.15 & 0.17 & 0.24 & 0.21 & 0.23 & 0.24 \\
& 0.28 & 0.33 & 0.35 & 0.20 & 0.39 & 0.48 \\
Balochistan & 0.03 & 0.13 & 0.19 & 0.08 & 0.19 & 0.22 \\
Khyber Pakhtunkhwa & 0.23 & 0.53 & 0.66 & 0.09 & 0.21 & 0.23 \\
Punjab & 0.26 & 0.28 & 0.43 & 0.21 & 0.23 & 0.24 \\
Sindh & 0.26 & 0.27 & 0.32 & 0.21 & 0.24 & 0.25 \\
Islamabad Capital Territory & Doctors \\
Pakistan & &
\end{tabular}

Source: extrapolated from growth in Pakistan population, 1998 census (Department of Statistics). differences are seen in the responses for work environment across age or gender subcategories, or for years of service and BPS categories, but there are significant differences between urban and rural facilities.

The survey results show that positive aspects of the work environment grow stronger with the size of the public sector health facility. The smallest facilities - dispensaries and basic health units - face the largest constraints in terms of logistics and supplies in the opinion of the sampled health workers from such facilities. Teaching hospitals are the best resourced with supplies and logistics as well as machinery and equipment. The larger provinces (Punjab and
Sindh) have better scores for supplies and logistics, machinery and equipment compared with Balochistan or Khyber Pakhtunkhwa. The score on composite poor for Balochistan. This composite index captures responses related to clean drinking water, transport, security, food and uniforms for the health workers at the facility. Punjab and Sindh also perform significantly better on cumulative indicators. The score achieved by Punjab, the most populous province, mirrors the higher performance of the province on job satisfaction of sampled health workers. Federal workers show reservations about their organizational culture. administrative facilitation is particularly

\begin{tabular}{lcccc}
\hline $\begin{array}{l}\text { Table } 4 \text { Composite scores on job satisfaction and work environment indices, by } \\
\text { location and sector }{ }^{\text {a }}\end{array}$ & Urban & Rural & Public & Private \\
\hline $\begin{array}{l}\text { Description of composite indices } \\
\text { Recruitment/career development/skills }\end{array}$ & 2.5 & 2.4 & 2.5 & 2.5 \\
$\quad$ and abilities & 3.0 & 3.3 & 3.3 & 2.6 \\
Benefits and grievances & 3.3 & 3.6 & 3.8 & 2.7 \\
Salary & 2.3 & 2.3 & 2.4 & 2.0 \\
Motivation, recognition and respect & 2.2 & 2.3 & 2.4 & 2.0 \\
Professional facilitation & 2.6 & 3.0 & 3.0 & 2.2 \\
Workload & 1.8 & 1.9 & 1.9 & 1.7 \\
Retention & 2.0 & 2.9 & 2.8 & 1.6 \\
Infrastructure & 2.5 & 3.3 & 3.0 & 2.5 \\
Logistics and supplies & 1.8 & 2.5 & 2.5 & 1.4 \\
Machinery and equipment & 2.5 & 2.5 & 2.6 & 2.3 \\
Organizational culture & 3.1 & 3.6 & 3.5 & 2.9 \\
Administrative facilitation & & & & \\
Work environment (cumulative question, & 1.6 & 1.8 & 1.8 & 1.3 \\
\hline positive) & & &
\end{tabular}

${ }^{a}$ Lower score is a better and more positive indication.

\section{Discussion}

The problem in health service delivery in Pakistan has not been the unavailability of physical health facilities, but rather their poor utilization and inability to yield desired health outcomes [8]. Equipping health facilities with adequate, well-trained and motivated health workers is the first step in improving utilization and quality of care. In order to address HRH issues in the country, we need to know the distribution of health workers across Pakistan, their total numbers, in terms of population, health needs and in proportion to each other (e.g. nurse:doctor ratios). Similarly, to improve utilization and quality of public health care services, we need to assess the job satisfaction and motivation of health care service providers.

The present survey is one of the largest surveys of health care workers conducted in Pakistan to assess their numbers and understand the realities of their work conditions, motivation, job satisfaction and the adequacy of their equipment and instruments. The median estimate of total health workers employed in the district health system in the public sector for 2009 is 417288 ; this number does not include tertiary hospitals, or provincial, district or federal staff at Ministry of Health offices involved in planning, budgeting, training or research. The median estimate of district doctors, both general practitioners and specialists (not including dentists) in Pakistan for 2009 is 46153 in the public sector, which compares with an earlier estimate of 74000 doctors in Pakistan in 2005 across public and private sectors [9]. Estimates for tertiary hospitals show that Punjab and Sindh provinces have the highest number of doctors. This is substantiated by Pakistan Medical and Dental Council data, which show that Sindh has the highest number of registered doctors in both public and private sectors [10], followed by Punjab. 
Pakistan has a shortage of nurses, further exacerbated by maldistribution across provinces. This shortage is particularly pronounced in Sindh, where they may not be adequate nurses and midwives to assist doctors. In contrast, Khyber Pakhtunkhwa has the highest numbers of nursing staff, both as a total and as a ratio to the population. The number of nurses and midwives is particularly important in relation to the MDG target of all deliveries to be attended by skilled birth attendants, because this shortage will be a barrier to achieving the desired target. The shortage of managerial and administrative staff is also a challenge for a country with the health care delivery complexity that Pakistan faces. Attrition in doctors or nurses in the public sector does not appear to be significant.

The presence of a large workforce of lady health workers (almost 100000 ) has favourably affected the population:health worker ratio and gender balance in the public sector in Pakistan. It is particularly pertinent to note that this large number is deployed in rural areas and is targeted towards the rural poor who have minimal or no access to the private sector. The importance of this cadre for making crucial progress towards MDG 4 and 5 has been recognized and the Global Health Workforce Alliance, in a recent meeting, Global consultation on community health workers, 29-30 April 2010, has concluded that community health workers should be included in the formal health systems of countries. The global body has recommended bringing about uniformity in the selection, training, operation and other aspects of community health workers all over the world.

The HRH policy dimension, though very critical, is a less revealing area and survey results showed varying levels of development and implementation of HRH policies. This area needs further exploration and insight.

The role of job satisfaction and the work environment on retention and recruitment is increasingly recognized [11]. Health workers may feel demotivated if their organization has not equipped their facility with the right equipment and supplies and a good infrastructure [12]. The results for job satisfaction indicate that, in general, publicsector health workers are neither satisfied nor dissatisfied but are broadly neutral. Based on specific, related questions, there is an indication that public health workers across the cadres do not intend to leave. Male workers were slightly less dissatisfied with their salary and compensation than female workers. Urban workers are inclined to think more positively about their workload than rural workers. The pay scales at federal or provincial levels are not related to any distinct patterns of differences in job satisfaction. Regular employees are less satisfied on salary, motivation/recognition and professional facilitation compared with their contractual colleagues. Regarding the work environment, the focus of assessment was on general issues such as organizational culture and administrative facilitation. Health workers from Punjab (both public and private), have the best job satisfaction scores compared with provinces and the federal Ministry of Health.

While there is considerable salaryrelated dissatisfaction in the public sector at all levels compared with the private sector, this does not necessarily translate into a choice or desire to work elsewhere, either full-time or part-time. We believe that there is evidence for a lack of salary-related "push" factors for attrition in the public sector. For the employees dissatisfied with salary, the overall dissatisfaction with working for their organization was quite high. Though the salary-related dissatisfaction rates are lower than for the private sector, the "push" from such dissatisfaction is much stronger in the private sector than in the public sector.

Regarding work environment, there are large differences between the public and private sectors. The private sector outstrips the public sector on all aspects of work environment. The differences are particularly clear for facility-level infrastructure, machinery and equipment, and administrative facilitation. Overall, considering both the job satisfaction as well as the work environment analysis, there is an indication that health facilities in Punjab province are much better than in other provinces.

In conclusion, this HRH assessment provides a wealth of information that could be used for policy formation and to provide a basis for further steps, including: development of strategies and plans; development of national HRH observatories; establishment of national HRH coordination mechanisms; building national $\mathrm{HRH}$ expertise, including leadership and management capacity; and primary health care orientation of the health workforce. Countries facing a HRH crisis could benefit from each others' experiences and develop a mutual mechanism for HRH capacity building, with the help of WHO and other development partners.

\section{Acknowledgement}

This study was conducted with financial and technical support from the Global Health Workforce Alliance, WHO and the United States Agency for International Development (USAID), Pakistan. 


\section{References}

1. The world health report 2006: working together for health. Geneva, World Health Organization, 2006.

2. Economic survey of Pakistan 2008-09. Islamabad, Finance Division, 2009.

3. World health report 2002 - reducing risks, promoting healthy life. Geneva, World Health Organization, 2002.

4. Birch $\mathrm{S}$ et al. Human resource planning and the production of health: a needs-based analytical framework. Canadian Public Policy, 2007, 33(Suppl.):S1-S16.

5. Global atlas of the health workforce. Geneva, World Health Organization (http://www.who.int/globalatlas, accessed 12 December 2009).

6. Narasimhan $\mathrm{V}$ et al. Responding to the global human resources crisis. Lancet, 2004, 363:1469-1472.
7. National health policy 2009. Islamabad, Ministry of Health (final draft) (http://www.health.gov.pk, accessed 5 May 2010).

8. Medium term development framework 2005-2010. Islamabad, Planning and Development Commission, 2008.

9. Talati JJ, Pappas G. Migration, medical education, and health care: a view from Pakistan. Academic Medicine, 2006, 81(Suppl.);S55-S62.

10. Pakistan Medical and Dental Council, Islamabad [website] (www.pmdc.gov.pk, accessed 12 December 2009).

11. McAuliffe E et al. Measuring and managing the work environment of the mid-level provider - the neglected human resource. Human Resources for Health, 2009, 7:13.

12. Dieleman $\mathrm{M}$ et al. Identifying factors for job motivation of rural health workers in North Viet Nam. Human Resources for Health, 2003, 1:10. 